OPEN ACCESS

Edited by:

Aaron Beeler,

Boston University, United States

Reviewed by:

Pawan Kumar

University of Calgary, Canada

Raju Kumar Gupta,

Indian Institute of Technology Kanpur.

India

*Correspondence:

Zacharias Amara

zacharias.amara@lecnam.net

Specialty section:

This article was submitted to Microfluidic Engineering and Process

Intensification,

a section of the journal

Frontiers in Chemical Engineering

Received: 02 August 2021

Accepted: 19 October 2021

Published: 24 November 2021

Citation:

Lancel M, Gomez C, Port M and Amara Z (2021) Performances of

Homogeneous and Heterogenized Methylene Blue on Silica Under Red Light in Batch and Continuous Flow

Photochemical Reactors.

Front. Chem. Eng. 3:752364.

doi: 10.3389/fceng.2021.752364

\section{Performances of Homogeneous and Heterogenized Methylene Blue on Silica Under Red Light in Batch and Continuous Flow Photochemical Reactors}

\author{
Maxime Lancel, Catherine Gomez, Marc Port and Zacharias Amara * \\ Équipe de Chimie Moléculaire, Laboratoire de Génomique, Bioinformatique et Chimie Moléculaire, (GBCM), EA7528, \\ Conservatoire National des Arts et Métiers, HESAM Université, Paris, France
}

Methylene blue was efficiently immobilized on silica micro- and nanoparticles by electrostatic interactions and the performances of the heterogenized photocatalysts were compared against the homogeneous conditions using the photooxidation of citronellol as a model reaction under red light, in a batch and a continuous flow photochemical reactor. In batch, the heterogeneous photocatalyst outperforms the homogeneous one, presumably due to kinetic and stability effects. The two catalytic systems are also compared in a flow reactor displaying improved mass transfer properties. We demonstrate that this results in a dramatic enhancement in photocatalyst stability, reactivity and productivity. This study highlights the importance of photocatalyst stability under homogeneous versus heterogenized conditions and in batch versus flow photochemistry.

Keywords: photochemistry, flow chemistry, green chemistry, heterogeneous photocatalysis, catalysis, singlet oxygen, process intensifcation

\section{INTRODUCTION}

Visible-light photochemistry is a promising approach in the development of greener synthetic chemistry. This technology has been widely developed over the past two decades as it promotes a variety of powerful transformations under very mild conditions with increased selectivity and safety. The general principle is based on the use of a colored material, which is able to capture and transfer the energy of visible light to enable chemical reactivity. The basis of most of the developments in visible-light photochemistry is therefore linked to the properties of excited states dyes, so called photocatalysts (PCs), which are able to transfer energy or electrons to other reactants and catalyze a photochemical transformation (Prier et al., 2013). Excited state chemistry allows for conventional reactions to occur at close to ambient temperature, a landmark example being the photo-Ullmann reaction (Ziegler et al., 2013; Yoo et al., 2015), but also to generate unconventional electronic transitions, leading to completely new reactivity such as for instance $[2+2]$ cycloadditions which are impossible via thermal activation (Sarkar et al., 2020).

However, these molecular systems have important efficiency issues, which must be solved to make them more productive and ultimately applicable in an industrial context. PCs can generate important toxicity, cost and sustainability issues. They often display poor stability with low to mediocre turn over numbers (TONs) and their utilization often requires additional downstream purifications. In addition, an important issue in photocatalysis, which is often overlooked, is the problem of solubility of these reactive dyes, which makes them incompatible with the use of green solvents (Clarke et al., 
2018) and often impairs the overall benefit of visible-light photochemistry in terms of green chemistry.

To counter such sustainability issues, our group and others have developed recyclable photocatalytic systems, such as heterogenized solid PCs (Mori et al., 2010; Mori and Yamashita, 2016; Tambosco et al., 2018; Choi et al., 2020; Gisbertz and Pieber, 2020; Soria-Castro et al., 2020; Materna and Hammarström, 2021). In particular, we investigated the straightforward non-covalent immobilization of PCs on silica particles which resulted in an improved reactivity and stability (Tambosco et al., 2018), and provided additional physical properties such as magnetism (Terra et al., 2020) or plasmonic resonance (Gellé et al., 2021). We also developed a continuous flow photochemical process with a fixed photocatalytic bed reactor to leverage productivity issues (Blanchard et al., 2020). Important efforts have been made to intensify photochemical processes by means of flow chemistry and this technology is the most promising for larger-scale photochemical manufacturing. However, this approach remains limited to homogeneous or gas/liquid conditions and yet, processing heterogeneous solid/liquid and solid/liquid/gas reactions is still underdeveloped (Carofiglio et al., 2008; Woźnica et al., 2014; Amara et al., 2015; Mendoza et al., 2018; Pieber et al., 2018; Blanchard et al., 2020; Mendoza et al., 2020; Radjagobalou et al., 2020).

Another important parameter in photochemistry is the choice of the irradiation wavelength. Recent developments in photocatalysis have shown that red light is a powerful mean to increase productivity because of its excellent penetration depth even in highly concentrated colored or turbid media (Mei et al., 2020; Ogura et al., 2020). In addition, red light is also more thermally efficient since less energy is wasted in the PS compared to UV/Vis-PS. Therefore, for a given quantum yield, the energy efficiency is only related to the energy of the incident photons as non-radiative dissipation is less energetic. At the same time, if the reaction matrix absorbs less light, there will be less of a cooling requirement compared to UV/Vis-light. These factors explain why lower energy light photochemistry can be more successfully intensified in batch or flow reactors compared to actual UV/Vislight photochemistry.

Methylene blue (MB) is one of the most important red-light photocatalysts with applications such as type I and type II photooxidations and in photoredox catalysis (Patel et al., 2021) such as hydroxylation of boronic acid (Pitre et al., 2013), trifluoromethylation reactions (Romero and Nicewicz, 2016), photo-induced thiophosphonate synthesis (Zhang et al., 2018), dehydrosulfurization of thioamides to nitriles (Xu et al., 2020), acyl radical epoxyacylation of olefins (de Souza et al., 2018) and acyl radical-mediated intramolecular cyclization of aromatic acids (Hu et al., 2020). It is commercially available in large quantities at a low cost and it is relatively nontoxic and FDA approved for diagnostic applications ( $\mathrm{Oz}$ et al., 2011). It is also available with very high purity which is useful for studying its photochemical properties. However, it is known to be relatively unstable and therefore it represents an interesting model for understanding which reaction parameters affect PC stability the most (Nassar et al., 2019).

In this paper, we report on the development of a new photocatalytic system, displaying high efficiency under redlight, which is based on the immobilization of methylene blue (MB) on silica $\left(\mathrm{SiO}_{2}\right)$. The performances of the homogeneous and heterogeneous PCs (using micro- and nanoparticles) are compared in a batch and in a continuous flow photo-reactor under red light, using the benchmark photo-oxidation of $\beta$-citronellol (1), a key step in the industrial synthesis of the commercial fragrance rose oxide (Ravelli et al., 2011).

\section{RESULTS AND DISCUSSION}

MB produces singlet oxygen $\left({ }^{1} \mathrm{O}_{2}\right)$ with a good quantum yield $\left(\Phi_{\Delta}=\right.$ 0.60 in $\mathrm{CH}_{3} \mathrm{CN}$, Rossi et al., 2008) and has been applied in ${ }^{1} \mathrm{O}_{2}$ photooxidation reactions on several occasions (Nilsson et al., 1972; Matheson et al., 1975; Jahnke and Frenkel, 1978; Cocquet et al., 2000; Oelgemöller et al., 2006; Lancefield et al., 2012; Schachtner et al., 2016). The main drawback of MB is its tendency to agglomerate and its intermolecular reactivity leads to the formation of leuco-forms which account for a low stability in solution (Nassar et al., 2019). Building on our previously developed non-covalent immobilization approach of cationic dyes on $\mathrm{SiO}_{2}$, we succeeded in dispersing $\mathrm{MB}$ on micro- and nano- $\mathrm{SiO}_{2}$ particles by simply mixing the two components together in water (Figure 1A). The microparticles are commercially available and widely utilized in gel chromatography with a size of 40-60 $\mu \mathrm{m}$. The nanoparticles were obtained by the Stöber method with an average size of $187 \mathrm{~nm}$ determined by SEM and $190 \pm 50$ by DLS (Thomassen et al., 2010). $\mathrm{MB}$ has a large absorption band at $653 \mathrm{~nm}$ in $\mathrm{CH}_{3} \mathrm{CN}$ and a weaker band at $605 \mathrm{~nm}$. We observed after immobilization of $1.25 \mathrm{mg}$ of $\mathrm{MB}$ on $1 \mathrm{~g}$ of $\mathrm{SiO}_{2}$ micro- (MB@SiO $2 \mathrm{MPs}$ ) and nano-particles (MB@ $\mathrm{SiO}_{2} \mathrm{NPs}$ ), a blue shift of the maximum absorbance from 653 to $647 \mathrm{~nm}$ (MB@SiO $\left.{ }_{2} \mathrm{MPs}\right)$, and to $642 \mathrm{~nm}\left(\mathrm{MB} @ \mathrm{MiO}_{2} \mathrm{NPs}\right)$ (Figure 1B). This blue shift has been described in the literature and could be due to electrostatic interactions between $\mathrm{MB}$ and surface groups (He et al., 2009; Veerapandian and Yun, 2013) or to disaggregation via surface interaction. We confirmed the noncovalent nature of the interaction by fluorescence microscopy by adding pure $\mathrm{SiO}_{2}$ particles to a slurry of $\mathrm{MB} @ \mathrm{SiO}_{2}(1.25 \mathrm{mg} / \mathrm{g})$ and by observing the homogeneous fluorescence of all particles (Figure 1C). This experiment is in agreement with an adsorption/desorption equilibrium occurring in between the solid and liquid phases. We have previously shown (Terra et al., 2020) that the excited state lifetime of $\mathrm{Ru}$ (bpy) ${ }_{3} \mathrm{Cl}_{2}$ was not affected by immobilization on silica or on magnetic iron/silica nanoparticles and believe that, the excited state properties of $\mathrm{MB}$ remain the same whether in solution or immobilized on silica nanoparticles.

With these characterizations in hand, we used $\mathrm{MB}$ under homogeneous and heterogeneous conditions as a PC in the photooxidation of $\beta$-citronellol (1) (Figure 2). This reaction was first performed in a batch reactor with a concentration of 1 of $0.1 \mathrm{M}$ in $\mathrm{CH}_{3} \mathrm{CN}, 0.016 \mathrm{~mol} \%$ of PC under red light irradiation $(630 \mathrm{~nm}, 304$ LEDs, 30.4 W) for $4 \mathrm{~h}^{1}{ }^{1}$ As shown in Figure 2A, homogeneous MB

${ }^{1} \mathrm{We}$ initially performed control experiments on the conversion of 1,5dihydroxynaphthalene to produce juglone, a natural product and important intermediate in the synthesis of anthraquinones. In these experiments the performances of various $\mathrm{MB} @ \mathrm{SiO}_{2}$ density were assessed (see ESI) and we found that $1.25 \mathrm{mg} / \mathrm{g}$ of $\mathrm{MB} @ \mathrm{SiO}_{2}$ was the optimal concentration. 
A A<smiles></smiles>

B

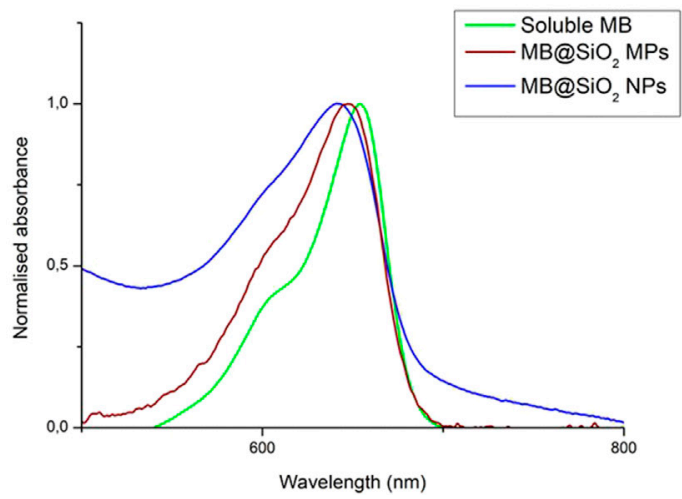

C

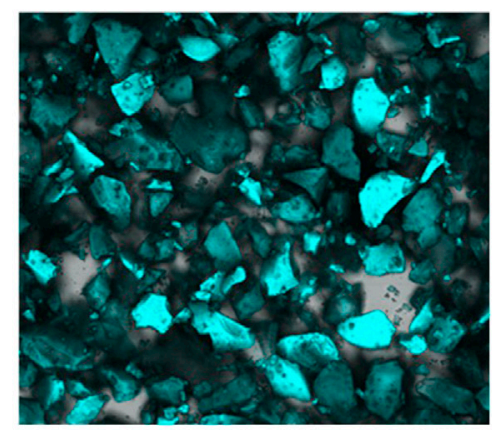

FIGURE 1 | (A) Structure of $\mathrm{MB}$ and process for the heterogenization of $\mathrm{MB}$ on $\mathrm{SiO}_{2}$; (B) Absorption spectra of $\mathrm{MB}$ (green) and dispersed $\mathrm{MB}_{\mathrm{S}} \mathrm{SiO} \mathrm{M}_{2} \mathrm{MPs}$ (blue) and $\mathrm{MB} @ \mathrm{SiO}_{2} \mathrm{NPs}$ (red) in $\mathrm{CH}_{3} \mathrm{CN}$; (C) Fluorescence microscopy snapshot of $\mathrm{MB}_{\mathrm{S}} \mathrm{SiO}_{2} \mathrm{MPs}$ treated with pure $\mathrm{SiO}_{2} \mathrm{MPs}$ in $\mathrm{CH}_{3} \mathrm{CN}$.
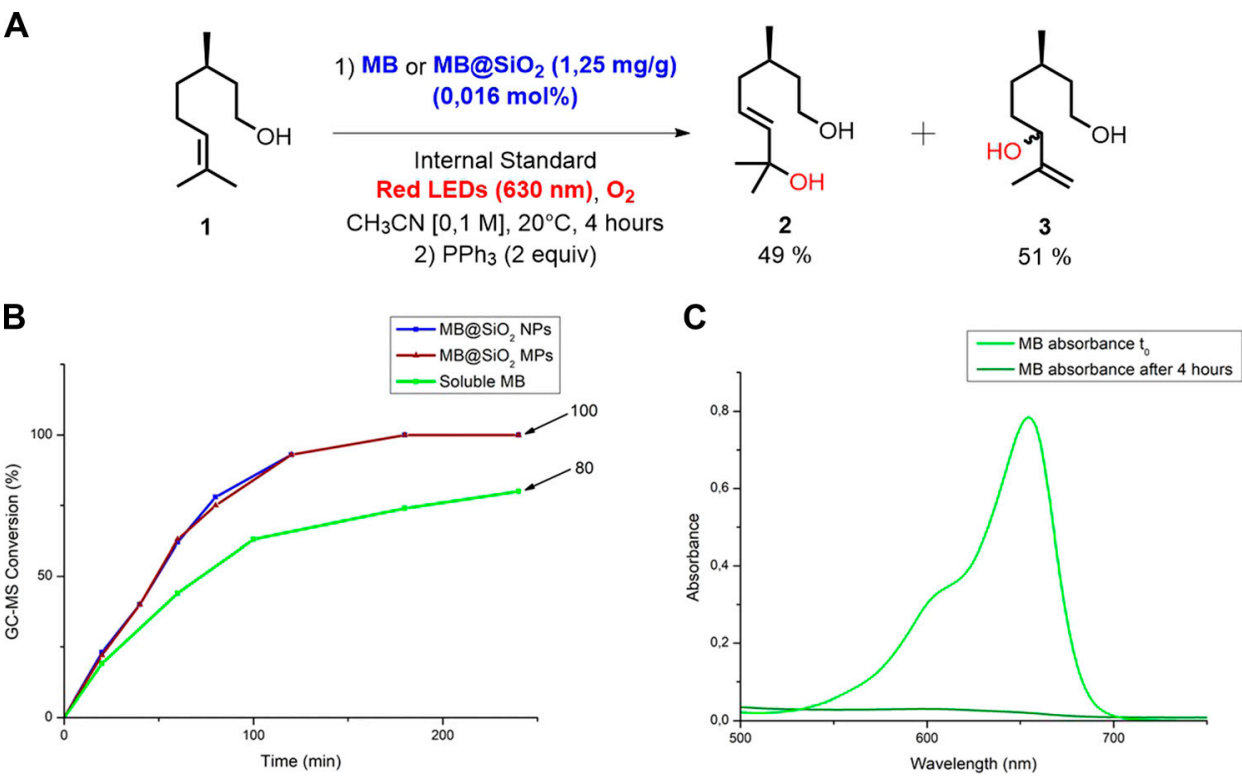

FIGURE 2 | (A) Photooxidation of $\mathbf{1}$ using MB or $\mathrm{MB} / \mathrm{SiO}_{2}$ as a PC under red light irradiation (630 nm) (B) Monitoring of the conversion of $\mathbf{1}$ to $\mathbf{2}$ and $\mathbf{3}$ in a batch reactor, in function of time by GC-MS analysis (Internal Standard $=1$,3-dimethoxybenzene). The ratio between $\mathbf{2}$ and $\mathbf{3}$ is measured by ${ }^{1} \mathrm{H}$ NMR spectroscopy. (C) Absorption spectra of the homogeneous reaction media obtained at $t_{0}$ and after $4 \mathrm{~h}$ of reaction.

provided $80 \%$ conversion and a $49 / 51$ selectivity to the regio-isomers 2 and 3 after $4 \mathrm{~h}$ of reaction, which corresponds to a turnover number (TON) of 5,000 and a space-time yield (STY) of $3.44 \mathrm{~g} \mathrm{~h}^{-1} \mathrm{~L}^{-1}$. On the other hand, we tested the supported PCs ${\mathrm{MB} @ S i \mathrm{O}_{2}}_{2} \mathrm{MPs}$ and $\mathrm{MB} @$ $\mathrm{SiO}_{2} \mathrm{NPs}$ and found a very close reactivity between the two immobilized systems, reaching $100 \%$ conversion within $3 \mathrm{~h}$, which corresponds to a TON of 6,250 and a STY of $5.74 \mathrm{~g} \mathrm{~h}^{-1} \mathrm{~L}^{-1}$. In these experiments, free $\mathrm{MB}$ is easily deactivated which explains the plateau obtained at $80 \%$, while $\mathrm{MB} @ S i O_{2}$ enables full conversion of $\mathbf{1}$ (Figure 2B). The complete deactivation of homogeneous MB is confirmed by the flattening of the absorption curve in the absorption spectra of the crude reaction medium taken at the end 
A
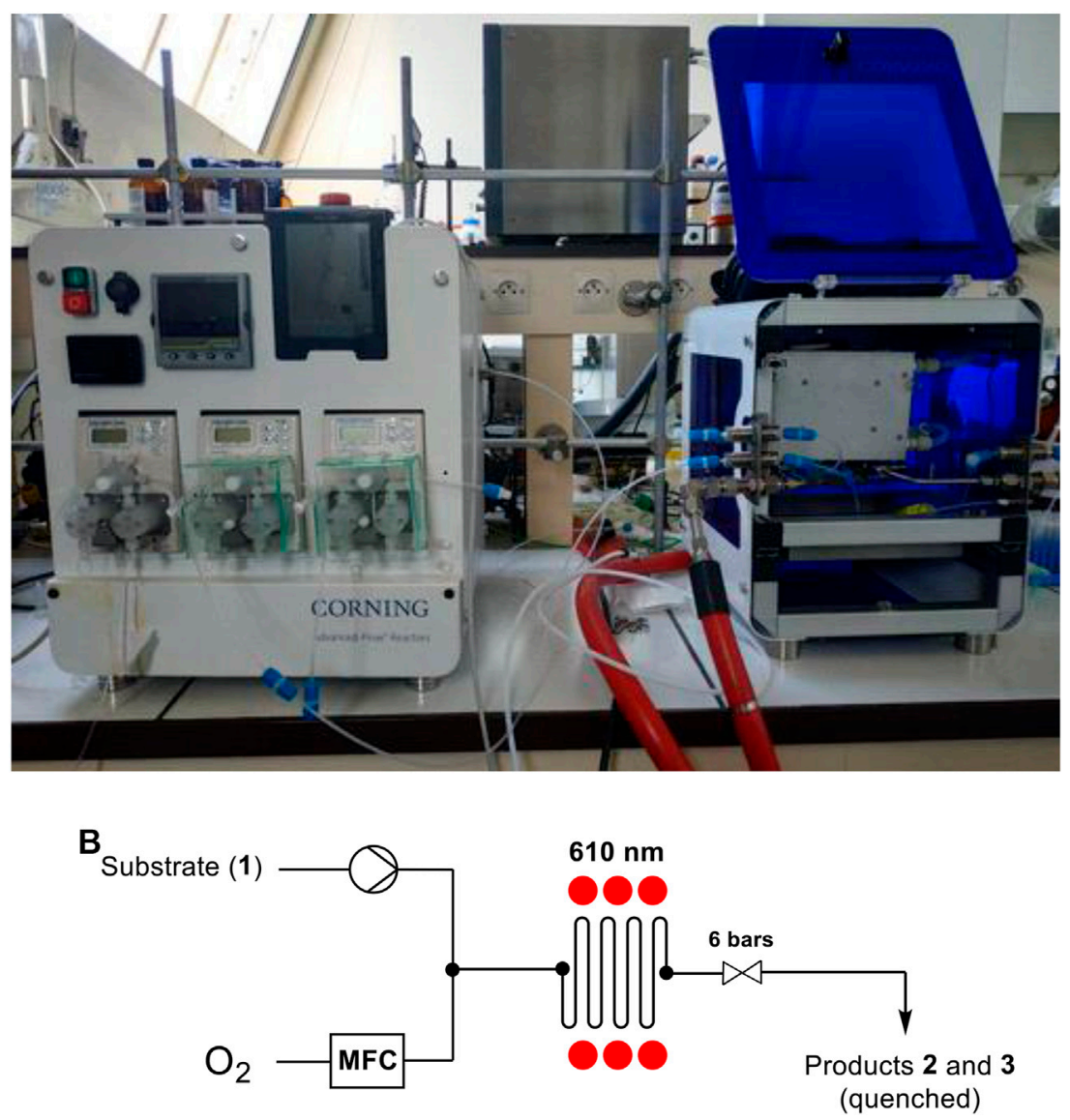

FIGURE 3 | (A) Picture of Corning ${ }^{\circledR}$ Advanced-Flow Lab Photoreactor (AFR) (B) Schematic diagram of the photoreactor.

of the reaction, after $4 \mathrm{~h}$ (Figure 2C). We compared the performances of these photocatalytic systems at $0^{\circ} \mathrm{C}$ and $40^{\circ} \mathrm{C}$ and found no difference in conversion rates compared to the close to ambient temperature $\left(20^{\circ} \mathrm{C}\right)$ reactions. Control experiments performed in the dark or under red-light without MB did not show any conversion of the starting material.

We next investigated the performances of the homogeneous and heterogeneous systems, using the same model reaction, in a continuous flow photoreactor consisting of a $2.7 \mathrm{ml}$ transparent plate with narrow channels and a heart-shaped static mixer with optimized mass transfer properties. (Horn and Gremetz, 2020). The plate is irradiated with interchangeable tunable LEDs and connected upstream to an HPLC pump, a mass flow controller (MFC), which is itself connected to an $\mathrm{O}_{2}$ cylinder, and downstream to a back pressure regulator (Figure 3).

Unfortunately, this reactor was not compatible with the use of micro-sized $\mathrm{SiO}_{2}$ particles due to clogging issues but nano-sized $\mathrm{SiO}_{2}$ particles were utilized without blockage. The first parameter we optimized for was the residence time, by fixing the $\mathrm{O}_{2}$ flowrate at $2.0 \mathrm{ml}(\mathrm{n}) \cdot \mathrm{min}^{-1}$, the temperature at $20^{\circ} \mathrm{C}$ and the system pressure at 6 bars. The selected wavelength was $610 \mathrm{~nm}$ and the lamp was operated at full power. We first operated under homogeneous conditions, with soluble $\mathrm{MB}(0.016 \mathrm{~mol} \%)$, by fixing the organic flowrate to $1.0 \mathrm{ml} \cdot \mathrm{min}^{-1}$ (Table 1, entry 1), corresponding to a $2.4 \mathrm{~min}$ residence time. Such conditions yielded $35 \%$ conversion of 1 and a $48 / 52$ selectivity between 2 and 3. Reducing the organic flow rate to $0.5 \mathrm{ml} \cdot \mathrm{min}^{-1}(4.9 \mathrm{~min}$ residence time) and then to $0.25 \mathrm{ml} \cdot \mathrm{min}^{-1}$ ( $10.0 \mathrm{~min}$ residence time) resulted in an increase in conversion to 57 and $81 \%$ respectively (Entries 2 and 3). Finally, decreasing the oxygen flowrate from $2.0 \mathrm{ml}(\mathrm{n}) \cdot \mathrm{min}^{-1}$ to $1.0 \mathrm{ml}(\mathrm{n}) \cdot \mathrm{min}^{-1}$ led to a further increase in conversion to up to $92 \%$ (Entry 4). This last result corresponds to a STY of $88 \mathrm{~g} \mathrm{~h}^{-1} \mathrm{~L}^{-1}$ which is 26 times more important compared to the STY measured with the batch reactor. We then turned our attention to study the heterogeneous nanosized PC system. $\mathrm{MB} @ \mathrm{SiO}_{2} \mathrm{NPs}(1.25 \mathrm{mg} / \mathrm{g})$ provided a $26 \%$ conversion at $1.0 \mathrm{ml} \cdot \mathrm{min}^{-1}$ for the organic and $2.0 \mathrm{ml} \cdot \mathrm{min}^{-1}$ for the $\mathrm{O}_{2}$ flowrates (Table 1, entry 5). When the residence time was increased to 4.9 and $10 \mathrm{~min}$ (corresponding to a 0.5 and $0.25 \mathrm{ml} \cdot \mathrm{min}^{-1}$ flowrates) the conversions were increased to 49 and $75 \%$ respectively (Entries 6 and 7). Finally, while maintaining the organic flowrate at $0.25 \mathrm{ml} \cdot \mathrm{min}^{-1}$ and decreasing the $\mathrm{O}_{2}$ flowrate to $1.0 \mathrm{ml} \cdot \mathrm{min}^{-1}$, an $86 \%$ conversion was obtained 

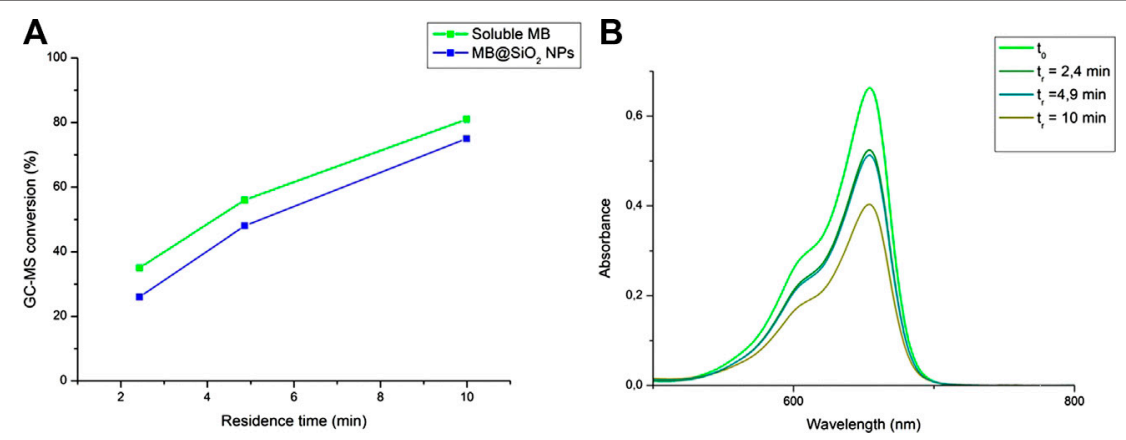

FIGURE 4 | (A) Plots of the conversions of $\mathbf{1}$ as a function of residence times under homogeneous and heterogeneous conditions in flow (in $\mathrm{CH}_{3} \mathrm{CN}$ [0.1 M], Q $\left(\mathrm{O}_{2}\right)=2 \mathrm{ml}(\mathrm{n}) \cdot \mathrm{min}^{-1}, p=6$ bars) (B) Absorption spectra of the homogeneous reaction media obtained at the outlet of the flow reactor at different residence times (in $\mathrm{CH}_{3} \mathrm{CN}[0.1 \mathrm{M}], \mathrm{Q}\left(\mathrm{O}_{2}\right)=2 \mathrm{ml}(\mathrm{n}) \cdot \mathrm{min}^{-1}, p=6$ bars).

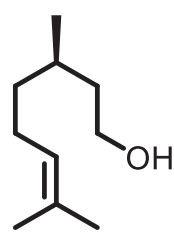

1

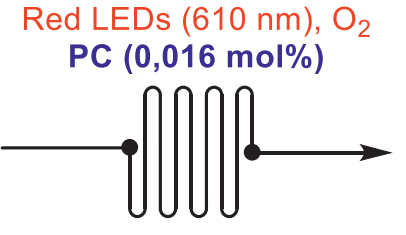

Internal Standard

$\mathrm{CH}_{3} \mathrm{CN}[0,1 \mathrm{M}], 20^{\circ} \mathrm{C}$ $P=6$ bars

(then quenching with $\mathrm{PPh}_{3}$ )

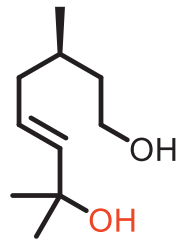

2

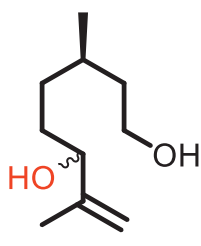

3

TABLE 1 | Conversions of 1 in a continuous flow reactor using MB and MB@SiO 2 NPs.

\begin{tabular}{|c|c|c|c|c|c|}
\hline Entry & $\mathrm{PC}$ & $\begin{array}{l}\text { Org Flow rate } \\
\left(\left(\mathrm{ml} \cdot \mathrm{min}^{-1}\right)\right.\end{array}$ & $\begin{array}{l}\mathrm{O}_{2} \text { Flow rate } \\
\left(\mathrm{ml}(\mathrm{n}) \cdot \mathrm{min}^{-1}\right)\end{array}$ & $\begin{array}{l}\text { Residence time } \\
\text { (min) }\end{array}$ & Conversion (\%) \\
\hline 1 & $\mathrm{MB}$ & 1.0 & 2.0 & 2.4 & 35 \\
\hline 2 & $\mathrm{MB}$ & 0.5 & 2.0 & 4.9 & 57 \\
\hline 3 & MB & 0.25 & 2.0 & 10.0 & 81 \\
\hline 4 & MB & 0.25 & 1.0 & 10.3 & 92 \\
\hline 5 & $\mathrm{MB} @ \mathrm{SiO}_{2} \mathrm{NPs}$ & 1.0 & 2.0 & 2.4 & 26 \\
\hline 6 & $\mathrm{MB} @ \mathrm{SiO}_{2} \mathrm{NPs}$ & 0.5 & 2.0 & 4.9 & 49 \\
\hline 7 & $\mathrm{MB} @ \mathrm{SiO}_{2} \mathrm{NPs}$ & 0.25 & 2.0 & 10.0 & 75 \\
\hline 8 & $\mathrm{MB} @ \mathrm{SiO}_{2} \mathrm{NPs}$ & 0.25 & 1.0 & 10.3 & 86 \\
\hline
\end{tabular}

a Measured by GC-MS using an internal standard (1,3-dimethoxybenzene).

(Entry 8). This corresponds to a STY of $82 \mathrm{~g} \mathrm{~h}^{-1} \mathrm{~L}^{-1}$ which is 14 times more important than in our previous batch reactor studies with the heterogeneous PCs.

These results show inverted performances of the homogeneous versus heterogeneous PCs in flow compared to batch (although this difference is less significant than with the results obtained in batch). Indeed, the heterogeneous PC systematically provides lower conversions compared to the homogeneous system in flow $((<10 \%)$, see Figure 4A), which is the opposite as what we observed in batch. Our assumption is that improved mass-transfer properties make the reaction much more efficient in flow which minimizes the influence of catalyst deactivation, as opposed to batch where the poorer reactivity makes catalyst deactivation a dominating kinetic effect. The latter also accounts for the non-linear increase in conversion in function of residence time as observed in Figure $\mathbf{4 A}$, as a longer residence time should induce higher catalyst deactivation. In order to assess this hypothesis, we compared the absorption spectra of the crude homogeneous reaction media obtained at the outlet of the flow reactor at different residence times (Figure 4B). Indeed, we observed a marked difference in the absorption intensity of $\mathrm{MB}$ of the starting solution and 4.9 and 10.0 min residence times. However, the stability of $\mathrm{MB}$ appears to be the same at 2.4 and 4.9 min residence times. 


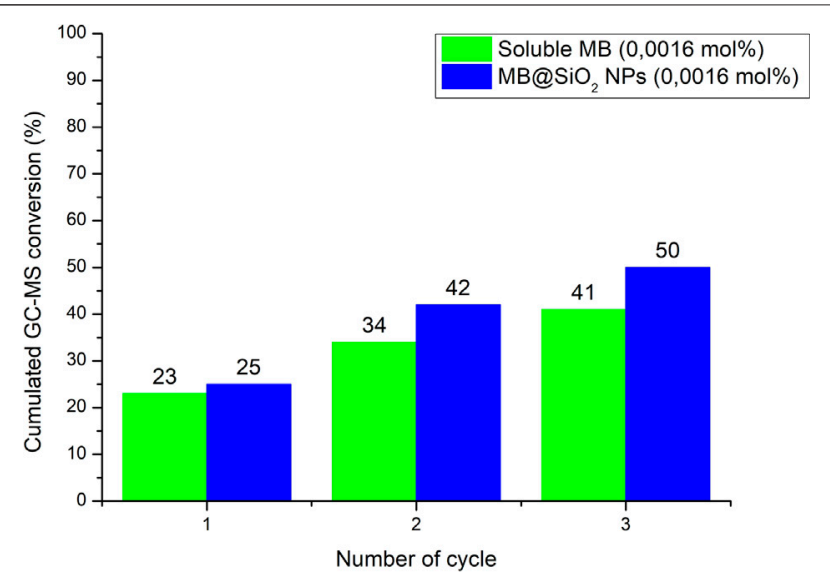

FIGURE 5 | Cumulated conversions of $\mathbf{1}$ as measured after $n$ cycles in the continuous flow photoreactor under the following conditions: in $\mathrm{CH}_{3} \mathrm{CN}[0.1 \mathrm{M}]$, $\mathrm{Q}$ (organic) $=0.25 \mathrm{ml} \cdot \mathrm{min}^{-1}, \mathrm{Q}\left(\mathrm{O}_{2}\right)=1.0 \mathrm{ml}(\mathrm{n}) \cdot \mathrm{min}^{-1}, p=6$ bars, $\mathrm{T}=20^{\circ} \mathrm{C}$ ).

TABLE 2 | Summary of stability and productivity values obtained in batch and flow photoreactors using $\mathrm{MB}$ and $\mathrm{MB} @ \mathrm{SiO}_{2} \mathrm{NPs}$ as PCs under red light irradiation.

\begin{tabular}{lcccc}
\hline & \multicolumn{2}{c}{ Batch } & \multicolumn{2}{c}{ Flow } \\
\hline PC & $\mathrm{MB}$ & $\mathrm{MB} @ \mathrm{SiO}_{2} \mathrm{NPS}$ & $\mathrm{MB}$ & $\mathrm{MB}_{\mathrm{NSiO}} \mathrm{NPS}$ \\
TON & 5,000 & 6,250 & 25,625 & 31,250 \\
STY $\left(\mathrm{g} \mathrm{h}^{-1} \mathrm{~L}^{-1}\right)$ & 3.44 & 5.74 & 88 & 82 \\
\hline
\end{tabular}

Although the process was not optimized in terms of productivity, these results already compare well with literature data. Our best productivity was calculated to be around $0.025 \mathrm{mmol} / \mathrm{min}$ which is close to a previously reported study using $\mathrm{MB}$, although with a higher $\mathrm{MB}$ loading, providing around $0.031 \mathrm{mmol} / \mathrm{min}$ at $1 \mathrm{~mol} \% \mathrm{MB}$ loading in the same reactor (Park et al., 2011). Other examples of higher productivity have been reported, however these required higher photocatalyst loading (1-20 mol\%) and were essentially performed on microchip reactors which offer a largely improved surface to volume ratio and therefore a much more improved irradiation of the reaction (Hamami et al., 2019).

In order to further evaluate these stability parameters under homogeneous and heterogenized conditions, we studied the photooxidation of $\mathbf{1}$ in the flow reactor under stressed catalytic conditions with a PC concentration 10 times lower than in our previous experiments $(0.016 \mathrm{~mol} \%)$. The purpose of these experiments is to determine cumulated TON (tTON) values in flow by recirculating the crude solution mixture and measuring the cumulated conversion after each cycle. The same experiment was carried out with $\mathrm{MB}$ and ${\mathrm{MB} @ S i \mathrm{~S}_{2}}_{2} \mathrm{NPs}$ and the results are plotted in Figure 5 These indicate a tTON of 25,625 for the homogeneous system $v s$ 31,250 for the heterogeneous system and demonstrate that photocatalyst stability is enhanced in the flow system, presumably due to less intense/prolonged exposure to light.

As a conclusion, we have reported in a systematic study the performances of a well-known PC (Methylene Blue) in a photooxidation reaction under homogeneous and heterogeneous conditions in a batch and in a flow reactor under red light (Table 2). Although the two reactors do not have the same photon throughput, the study highlights stability factors influencing the performances of the homogeneous and heterogeneous systems. Indeed, the homogeneous system seems to be less effective in a batch reactor due to rapid catalyst deactivation while this "unproductive" pathway is limited in flow compared to the "productive" photooxidation pathway, due to the improved mass transfer performances. On the other hand, the heterogeneous system provides a "protective" environment against catalyst deactivation which is leading to better performances in batch or in flow under stressed catalytic conditions, because in both experiments the photooxidation pathway is less efficient. Overall, we believe this study provides interesting data for the design and scale up of photochemical operations in industry, taking into account sustainability and process intensification parameters. In addition, this study indicates that high performance photocatalysis can be developed using low energy red light, which represents another important step towards the design of more environmentally benign photochemical manufacturing.

\section{DATA AVAILABILITY STATEMENT}

The original contributions presented in the study are included in the article/Supplementary Material, further inquiries can be directed to the corresponding author.

\section{AUTHOR CONTRIBUTIONS}

ML and ZA designed the project and experiments with the help of CG and MP. ML performed all the experiments. ML prepared and characterized the nanoparticles, with the help of CG. ML and ZA drafted the manuscript and all authors edited it.

\section{ACKNOWLEDGMENTS}

The authors are grateful to Corning ${ }^{\circledR}$ for the loan of an AdvancedFlow Lab Photoreactor (AFR) and to Marc Winter and Guillaume Gauron for fruitful discussions. Pr Audrey Moores and Julio C. S. Terra from University McGill are greatly acknowledged for the valuable discussions. The French Ministry of Higher Education, Research and Innovation and Doctoral School "Sciences des Métiers de l'Ingénieur" (ED 432) are gratefully acknowledged for a $\mathrm{PhD}$ scholarship attributed to ML. Maria Russo is gratefully acknowledged for fluorescence microscopy and transmission electron microscopy measurements.

\section{SUPPLEMENTARY MATERIAL}

The Supplementary Material for this article can be found online at: https://www.frontiersin.org/articles/10.3389/fceng.2021.752364/ full\#supplementary-material 


\section{REFERENCES}

Amara, Z., Bellamy, J. F. B., Horvath, R., Miller, S. J., Beeby, A., Burgard, A., et al. (2015). Applying green Chemistry to the Photochemical Route to Artemisinin. Nat. Chem. 7, 489-495. doi:10.1038/nchem.2261

Blanchard, V., Asbai, Z., Cottet, K., Boissonnat, G., Port, M., and Amara, Z. (2020). Continuous Flow Photo-Oxidations Using Supported Photocatalysts on Silica. Org. Process. Res. Dev. 24, 822-826. doi:10.1021/acs.oprd.9b00420

Carofiglio, T., Donnola, P., Maggini, M., Rossetto, M., and Rossi, E. (2008). Fullerene-Promoted Singlet-Oxygen Photochemical Oxygenations in GlassPolymer Microstructured Reactors. Adv. Synth. Catal. 350, 2815-2822. doi:10.1002/adsc.200800459

Choi, I. H., Yoon, S., Huh, S., Kim, S. J., and Kim, Y. (2020). Photophysical Properties and Heterogeneous Photoredox Catalytic Activities of Ru(bpy) 3 @InBTB Metal-Organic Framework (MOF). Chem. Eur. J. 26, 14580-14584. doi:10.1002/chem.202003743

Clarke, C. J., Tu, W.-C., Levers, O., Bröhl, A., and Hallett, J. P. (2018). Green and Sustainable Solvents in Chemical Processes. Chem. Rev. 118, 747-800. doi:10.1021/acs.chemrev.7b00571

Cocquet, G., Ferroud, C., Simon, P., and Taberna, P.-L. (2000). Single Electron Transfer Photoinduced Oxidation of Piperidine and Pyrrolidine Derivatives to the Corresponding Lactams. J. Chem. Soc. Perkin Trans. 2, 1147-1153. doi:10.1039/b001036g

de Souza, G. F. P., Bonacin, J. A., and Salles, A. G. (2018). Visible-Light-Driven Epoxyacylation and Hydroacylation of Olefins Using Methylene Blue/ Persulfate System in Water. J. Org. Chem. 83, 8331-8340. doi:10.1021/ acs.joc. 8 b01026

Gellé, A., Price, G. D., Voisard, F., Brodusch, N., Gauvin, R., Amara, Z., et al. (2021). Enhancing Singlet Oxygen Photocatalysis with Plasmonic Nanoparticles. ACS Appl. Mater. Inter. 13, 35606-35616. doi:10.1021/ acsami.1c05892

Gisbertz, S., and Pieber, B. (2020). Heterogeneous Photocatalysis in Organic Synthesis. ChemPhotoChem 4, 456-475. doi:10.1002/cptc.202000014

Hamami, Z. E., Vanoye, L., Fongarland, P., de Bellefon, C., and Favre-Réguillon, A. (2019). Improved Reactor Productivity for the Safe Photo-Oxidation of Citronellol under Visible Light LED Irradiation. ChemPhotoChem 3, 122-128. doi:10.1002/cptc.201800201

He, X., Wu, X., Wang, K., Shi, B., and Hai, L. (2009). Methylene Blue-Encapsulated Phosphonate-Terminated Silica Nanoparticles for Simultaneous In Vivo Imaging and Photodynamic Therapy. Biomaterials 30, 5601-5609. doi:10.1016/j.biomaterials.2009.06.030

Horn, C. R., and Gremetz, S. (2020). A Method to Determine the Correct Photocatalyst Concentration for Photooxidation Reactions Conducted in Continuous Flow Reactors. Beilstein J. Org. Chem. 16, 871-879. doi:10.3762/bjoc.16.78

$\mathrm{Hu}$, X.-Q., Liu, Z.-K., and Xiao, W.-J. (2020). Radical Carbonylative Synthesis of Heterocycles by Visible Light Photoredox Catalysis. Catalysts 10, 1054. doi:10.3390/catal10091054

Jahnke, L. S., and Frenkel, A. W. (1978). Photooxidation of Epinephrine Sensitized by Methylene Blue-Evidence for the Involvement of Singlet Oxygen and of Superoxide. Photochem. Photobiol. 28, 517-522. doi:10.1111/j.17511097.1978.tb06961.x

Lancefield, C. S., Zhou, L., Lébl, T., Slawin, A. M. Z., and Westwood, N. J. (2012). The Synthesis of Melohenine B and a Related Natural Product. Org. Lett. 14, 6166-6169. doi:10.1021/ol302859j

Materna, K. L., and Hammarström, L. (2021). Photoredox Catalysis Using Heterogenized Iridium Complexes**. Chem. Eur. J. 202101651. doi:10.1002/ chem.202101651

Matheson, I. B. C., Etheridge, R. D., Kratowich, N. R., and Lee, J. (1975). The Quenching of Singlet Oxygen by Amino Acids and Proteins. Photochem. Photobiol. 21, 165-171. doi:10.1111/j.1751-1097.1975.tb06647.x

Mei, L., Veleta, J. M., and Gianetti, T. L. (2020). Helical Carbenium Ion: A Versatile Organic Photoredox Catalyst for Red-Light-Mediated Reactions. J. Am. Chem. Soc. 142, 12056-12061. doi:10.1021/jacs.0c05507

Mendoza, C., Désert, A., Chateau, D., Monnereau, C., Khrouz, L., Lerouge, F., et al. (2020). Au nanobipyramids@mSiO2 Core-Shell Nanoparticles for PlasmonEnhanced Singlet Oxygen Photooxygenations in Segmented Flow Microreactors. Nanoscale Adv. 2, 5280-5287. doi:10.1039/D0NA00533A
Mendoza, C., Emmanuel, N., Páez, C. A., Dreesen, L., Monbaliu, J. C. M., and Heinrichs, B. (2018). Improving Continuous Flow Singlet Oxygen Photooxygenation Reactions with Functionalized Mesoporous Silica Nanoparticles. ChemPhotoChem 2, 890-897. doi:10.1002/ cptc. 201800148

Mori, K., Kawashima, M., Che, M., and Yamashita, H. (2010). Enhancement of the Photoinduced Oxidation Activity of a Ruthenium(II) Complex Anchored on Silica-Coated Silver Nanoparticles by Localized Surface Plasmon Resonance. Angew. Chem. 122, 8780-8783. doi:10.1002/ange.201004942

Mori, K., and Yamashita, H. (2016). Metal Complexes Supported on Solid Matrices for Visible-Light-Driven Molecular Transformations. Chem. Eur. J. 22, 11122-11137. doi:10.1002/chem.201600441

Nassar, S. J. M., Wills, C., and Harriman, A. (2019). Inhibition of the Photobleaching of Methylene Blue by Association with Urea. ChemPhotoChem 3, 1042-1049. doi:10.1002/cptc.201900141

Nilsson, R., Merkel, P. B., and Kearns, D. R. (1972). Unambiguous Evidence for the Participation of Singlet Oxygen $(\Delta)$ in Photodynamic Oxidation of Amino Acids. Photochem. Photobiol. 16, 117-124. doi:10.1111/j.17511097.1972.tb07343.x

Oelgemöller, M., Healy, N., de Oliveira, L., Jung, C., and Mattay, J. (2006) Green Photochemistry: Solar-Chemical Synthesis of Juglone with Medium Concentrated Sunlight. Green. Chem. 8, 831-834. doi:10.1039/B605906F

Ogura, A., Ichii, N., Shibata, K., and Takao, K.-i. (2020). Red-LightMediated Barton-McCombie Reaction. BCSJ 93, 936-941. doi:10.1246/ bcsj. 20200087

Oz, M., Lorke, D. E., Hasan, M., and Petroianu, G. A. (2011). Cellular and Molecular Actions of Methylene Blue in the Nervous System. Med. Res. Rev. 31, 93-117. doi:10.1002/med.20177

Park, C. P., Maurya, R. A., Lee, J. H., and Kim, D.-P. (2011). Efficient Photosensitized Oxygenations in Phase Contact Enhanced Microreactors. Lab. Chip 11, 1941. doi:10.1039/c1lc20071b

Patel, R. I., Sharma, A., Sharma, S., and Sharma, A. (2021). Visible Light-Mediated Applications of Methylene Blue in Organic Synthesis. Org. Chem. Front. 8, 1694-1718. doi:10.1039/D0QO01182G

Pieber, B., Shalom, M., Antonietti, M., Seeberger, P. H., and Gilmore, K. (2018). Continuous Heterogeneous Photocatalysis in Serial Micro-batch Reactors. Angew. Chem. Int. Ed. 57, 9976-9979. doi:10.1002/ anie. 201712568

Pitre, S. P., McTiernan, C. D., Ismaili, H., and Scaiano, J. C. (2013). Mechanistic Insights and Kinetic Analysis for the Oxidative Hydroxylation of Arylboronic Acids by Visible Light Photoredox Catalysis: A Metal-Free Alternative. J. Am. Chem. Soc. 135, 13286-13289. doi:10.1021/ja406311g

Prier, C. K., Rankic, D. A., and MacMillan, D. W. C. (2013). Visible Light Photoredox Catalysis with Transition Metal Complexes: Applications in Organic Synthesis. Chem. Rev. 113, 5322-5363. doi:10.1021/cr300503r

Radjagobalou, R., Blanco, J.-F., Petrizza, L., Le Bechec, M., Dechy-Cabaret, O., Lacombe, S., et al. (2020). Efficient Photooxygenation Process of Biosourced a-Terpinene by Combining Controlled LED-Driven Flow Photochemistry and Rose Bengal-Anchored Polymer Colloids. ACS Sustain. Chem. Eng. 8, 18568-18576. doi:10.1021/acssuschemeng.0c06627

Ravelli, D., Protti, S., Neri, P., Fagnoni, M., and Albini, A. (2011). Photochemical Technologies Assessed: the Case of Rose Oxide. Green. Chem. 13, 1876. doi:10.1039/c0gc00507j

Romero, N. A., and Nicewicz, D. A. (2016). Organic Photoredox Catalysis. Chem. Rev. 116, 10075-10166. doi:10.1021/acs.chemrev.6b00057

Rossi, L. M., Silva, P. R., Vono, L. L. R., Fernandes, A. U., Tada, D. B., and Baptista, M. S. (2008). Protoporphyrin IX Nanoparticle Carrier: Preparation, Optical Properties, and Singlet Oxygen Generation. Langmuir 24, 12534-12538. doi:10.1021/la800840k

Sarkar, D., Bera, N., and Ghosh, S. (2020). [2+2] Photochemical Cycloaddition in Organic Synthesis. Eur. J. Org. Chem. 2020, 1310-1326. doi:10.1002/ ejoc. 201901143

Schachtner, J., Bayer, P., and Jacobi von Wangelin, A. (2016). A Flow Reactor Setup for Photochemistry of Biphasic Gas/liquid Reactions. Beilstein J. Org. Chem. 12, 1798-1811. doi:10.3762/bjoc.12.170

Soria-Castro, S. M., Lebeau, B., Cormier, M., Neunlist, S., Daou, T. J., and Goddard, J.-P. (2020). Organic/Inorganic Heterogeneous Silica-Based Photoredox 
Catalyst for Aza-Henry Reactions. Eur. J. Org. Chem. 2020, 1572-1578. doi:10.1002/ejoc.201901382

Tambosco, B., Segura, K., Seyrig, C., Cabrera, D., Port, M., Ferroud, C., et al. (2018). Outer-Sphere Effects in Visible-Light Photochemical Oxidations with Immobilized and Recyclable Ruthenium Bipyridyl Salts. ACS Catal. 8, 4383-4389. doi:10.1021/acscatal.8b00890

Terra, J. C. S., Desgranges, A., Monnereau, C., Sanchez, E. H., De Toro, J. A., Amara, Z., et al. (2020). Photocatalysis Meets Magnetism: Designing Magnetically Recoverable Supports for Visible-Light Photocatalysis. ACS Appl. Mater. Inter. 12, 24895-24904. doi:10.1021/acsami.0c06126

Thomassen, L. C. J., Aerts, A., Rabolli, V., Lison, D., Gonzalez, L., Kirsch-Volders, M., et al. (2010). Synthesis and Characterization of Stable Monodisperse Silica Nanoparticle Sols for In Vitro Cytotoxicity Testing. Langmuir 26, 328-335. doi:10.1021/la902050k

Veerapandian, M., and Yun, K. (2013). Methylene Blue Dye Coated Silver-Silica Nanoparticles with Dual Functionality Fabricated by Injection Pump and Ultrasonochemistry. Mater. Res. Bull. 48, 1817-1823. doi:10.1016/ j.materresbull.2013.01.028

Woźnica, M., Chaoui, N., Taabache, S., and Blechert, S. (2014). THF: An Efficient Electron Donor in Continuous Flow Radical Cyclization Photocatalyzed by Graphitic Carbon Nitride. Chem. Eur. J. 20, 14624-14628. doi:10.1002/ chem. 201404440

Xu, T., Cao, T., Feng, Q., Shenlin, H., and Liao, S. (2020). Metal-Free Dehydrosulfurization of Thioamides to Nitriles Under Visible Light. Chem. Commun. 56, 5151-5153. doi:10.1039/D0CC01380C

Yoo, W.-J., Tsukamoto, T., and Kobayashi, S. (2015). Visible LightMediated Ullmann-type C-N Coupling Reactions of Carbazole
Derivatives and Aryl Iodides. Org. Lett. 17, 3640-3642. doi:10.1021/ acs.orglett.5b01645

Zhang, H., Zhan, Z., Lin, Y., Shi, Y., Li, G., Wang, Q., et al. (2018). Visible Light Photoredox Catalyzed Thiophosphate Synthesis Using Methylene Blue as a Promoter. Org. Chem. Front. 5, 1416-1422. doi:10.1039/C7QO01082F

Ziegler, D. T., Choi, J., Muñoz-Molina, J. M., Bissember, A. C., Peters, J. C., and Fu, G. C. (2013). A Versatile Approach to Ullmann C-N Couplings at Room Temperature: New Families of Nucleophiles and Electrophiles for Photoinduced, CopperCatalyzed Processes. J. Am. Chem. Soc. 135, 13107-13112. doi:10.1021/ja4060806

Conflict of Interest: The authors declare that the research was conducted in the absence of any commercial or financial relationships that could be construed as a potential conflict of interest.

Publisher's Note: All claims expressed in this article are solely those of the authors and do not necessarily represent those of their affiliated organizations, or those of the publisher, the editors and the reviewers. Any product that may be evaluated in this article, or claim that may be made by its manufacturer, is not guaranteed or endorsed by the publisher.

Copyright $\odot 2021$ Lancel, Gomez, Port and Amara. This is an open-access article distributed under the terms of the Creative Commons Attribution License (CC BY). The use, distribution or reproduction in other forums is permitted, provided the original author(s) and the copyright owner(s) are credited and that the original publication in this journal is cited, in accordance with accepted academic practice. No use, distribution or reproduction is permitted which does not comply with these terms. 